\title{
Assessment of Antioxidant Enzymes and Cortisol Levels among HIV Patients on HAART
}

\author{
Brown Holy ${ }^{1}$, Elechi-Amadi, Kemzi Nosike ${ }^{2}$ \\ ${ }^{1,2}$ Department of Medical Laboratory Science, Rivers State University of Science and Technology, Npkolu, Port Harcourt, Nigeria
}

\begin{abstract}
The chronic oxidative stress that HIV patients go through brought the need for assessment of the antioxidant levels into focus as an adjunct to the standard regiment of treating HIV patients. This study was on 116 HIV patients, of which 60 were receiving antiretroviral therapy and 56 were apparently healthy and age-matched individuals as control subjects. The bio-data and medical history of the subjects were obtained using questionnaire. These included duration of HIV infection and duration of antiretroviral treatment. The subjects that participated in this research gave their informed consent, did not have tuberculosis, diabetes or severe malaria; those with any of these conditions were excluded from the research. Female subjects who were pregnant were also excluded from the study. The subjects were within 20-70 years of age, and have had HIV for at least one year for the test group, while the control were HIV negative. Five millilitres of blood was collected from each subject after overnight fast, for the assay of glutathione peroxidase, superoxide dismutase, cortisol, and CD4. The result revealed that the mean values of GPX and SOD levels of HIV positive patients on HAART were significantly lower than the control $(p=0.0001)$. The mean cortisol levels of HIV patients on HAART were significantly higher than the control $(p=0.0001)$. Similar trend was observed in male and female categories. Based on the results, it is indicative that HIV patients are constantly under oxidative stress, HIV drug therapy and increased cortisol levels have negative effects on the immune status of HIV patients. The need to incorporate antioxidant in treatment regiment is advocated.
\end{abstract}

Keywords: Antioxidant, oxidative stress, cortisol, antiretroviral, superoxide dismutase

\section{Introduction}

The Human Immunodeficiency Virus (HIV) is a retro-virus that affects the $\mathrm{CD} 4^{+} \mathrm{T}$-Cells in humans, leading to a decline in immune response. This consequently leads to a condition known as Acquired Immunodeficiency Syndrome (AIDS) in humans [1]. HIV is a retrovirus, it carries genetic information in RNA rather DNA [2]. When it attaches to a host cell, the RNA is converted to DNA with the aid of the enzyme, Reverse Transcriptase. In the host's cell, there is a replication of the viral particle [2] As a result of this, there is immune suppression in HIV patients, leading to a diminished response to infection and tumours [2,3]. This is due to destruction of $\mathrm{CD}^{+} \mathrm{T}$-cells by HIV.

Free radicals, which include Reactive oxygen species (ROS) and Reactive Nitrogen Species (RNS) are produced by living organisms as a result of normal cellular metabolism. At low concentrations they perform beneficial physiological functions, through cellular responses and immune function, but at high concentrations they cause adverse modifications to the cellular components $[4,5]$. There are three major ROS that are of physiological importance in the human system. They include superoxide ion, hydroxyl radical and hydrogen peroxide, and they are endogenous oxidants. Other endogenous oxidants include hypochlorous acid, peroxyl radicals and hydroperoxyl radicals.

Most cells can produce superoxide, hydrogen peroxide and nitrogen oxide on demand [6].Also, antibodies, regardless of origin or antigenic specificity, could convert oxygen to hydrogen peroxide [7]. Endogenously the body generates ROS in the mitochondria, endoplasmic reticulum, phagocytosis and other metabolic sources. Superoxide radical is produced in the mitochondria through the electron transport chain. This radical is transformed into hydrogen peroxide, which can react with transition metals like iron and copper to form hydroxyl radicals [8].
There are also exogenous sources of oxidants. These include cigarette smoke, radiations and heavy metals. Cigarette smoke contains many oxidants and free radicals and organic compounds. When inhaled into the lungs there is an accumulation of neutrophils and macrophages, which further increase the injurious effects of the oxidants. Heavy metals induce cellular damage through lipid peroxidation and reactions with nuclear proteins and DNA [9].

The human body has a various antioxidants whose functions counterbalance the effects of the oxidant [10].These antioxidants can be divided into enzymatic and non enzymatic. The enzymatic oxidants in human system include glutathione peroxidase, superoxide dismutase and catalase, as the major ones $[4,10]$. Superoxide dismutase acts on superoxide radical while glutathione and catalase act on the peroxides, although the only substrate for catalase is hydrogen peroxide. Glutathione peroxidase acts on both hydrogen peroxide and all other types of peroxides.

HIV-infected patients have oxidative imbalance early in the disease, and there is formation of free radicals [11]. Thus, HIV infection increases oxidative stress which may result in oxidative damage [12]. Reactive oxygen species (ROS), which results from cellular reactions, may enhance viral replication by activating nuclear transcription factors, which ultimately leads to an increased rate of viral gene expression [13]. There is also an increased rate of $\mathrm{CD}^{+}$apoptosis in HIV infection. Thus, viral infections can interfere with metabolic and physiological mechanism of host cell. Since HIV thrives in the oxidized environment, the antioxidant defence system in human serum becomes insufficient to circumvent HIV replication secondary to cellular ROS production [14].

Cortisol is a hormone that is secreted in the adrenal gland. Its secretion is usually in response to the adrenocorticotropic 


\section{International Journal of Science and Research (IJSR) ISSN (Online): 2319-7064 \\ Index Copernicus Value (2013): 6.14 | Impact Factor (2015): 6.391}

hormone (ACTH) released from the pituitary gland [15]. ACTH is secreted in response to several factors, one of which is corticotrophin-releasing hormone (CRH), which is synthesized and released from the hypothalamus [15]. Another factor that increases the level of cortisol is stress, and it has been reported that HIV patients are under oxidative stress. Other factors that can increase ACTH level, and therefore cortisol, are pro-inflammatory cytokines, especially interleukin-1 and interleukin-6, and tumour necrosis factor $\alpha$ [16]. There is impairment of adrenal function in HIV patients. The interaction between HIV and endocrine system is complex [17]. This research therefore evaluated the levels of glutathione peroxidase and superoxide dismutase as a function of the antioxidant status of HIV patients.

\section{Materials and Method}

\subsection{Study Design}

This cross-sectional research work was carried out in 117 HIV patients, of which 60 were receiving antiretroviral therapy and 56 apparently healthy and age-matched individuals as control subjects. The bio-data and medical history of the subjects were obtained using questionnaire. These included duration of HIV infection and duration of antiretroviral treatment.

\subsection{Eligibility Criteria}

This study involved subjects with HIV infection. The subjects that participated in this research gave their informed consent, did not have tuberculosis, diabetes or severe malaria; those with any of these conditions were excluded from the research. Female subjects who were pregnant were also excluded from the study. The subjects were within 2070 years of age, and have had HIV for at least one year for the test group, while the control were HIV negative.

\subsection{Sample Collection}

Five millilitres of blood was collected from each subject after overnight fast, for the assay of glutathione peroxidase, superoxide dismutase, cortisol, and CD4. The blood samples were centrifuged at 3,000rpm for 10 minutes and the plasma separated and put in a plain bottle. The plasma samples were then preserved at $-20^{\circ} \mathrm{C}$ in the freezer prior to analysis. The analysis for CD4 cell was done same day while the assay of glutathione peroxidase, superoxide dismutase and cortisol were done on stored plasma after 4days.

\subsection{Statistical Analysis}

Data were analysed with Excel 2003 program (Excel Inc.) and Graphpad Prism, and expressed as mean \pm SD. Student ttest were used to compare values of measured parameters between HIV subjects and control subjects. P-values less than 0.05 were considered significant.

\section{Results}

3.1 Comparison of antoxidant enzyme levels of HIV subjects on HAART and control subjects.

There was a significant difference in the levels of CD4 $(p=0.0001)$. The mean value of GPX level of HIV patients on HAART significantly lower than the control $(p=0.0001)$. The mean value of SOD for HIV patients on HAART were significantly lower than the control $(p=0.0001)$. The mean value of cortisol for HIV patients on HAART was $83.98 \pm$ $62.55 \mathrm{ng} / \mathrm{ml}$ while that of control subjects was $42.83 \pm 21.0$ $\mathrm{ng} / \mathrm{ml}$. There was a significant difference in the levels of cortisol $(\mathrm{p}=0.0001)$.

Table 3.1: Showing mean values of parameters for HIV patients on HAART and control

\begin{tabular}{|c|c|c|c|c|}
\hline & & $G P X(\mathrm{ng} /$ & $\begin{array}{c}S O D(\mathrm{pg} / \\
\mathrm{ml})\end{array}$ & $\begin{array}{c}\text { Cortisol(ng } \\
/ \mathrm{ml})\end{array}$ \\
\hline HAART & $414.01 \pm$ & $0.51 \pm$ & $39.50 \pm$ & $83.98 \pm$ \\
$\mathrm{n}=60$ & 276.35 & 0.47 & 15.76 & 62.55 \\
\hline Control & $858.25 \pm$ & $0.56 \pm$ & $73.93 \pm$ & $42.83 \pm$ \\
$\mathrm{n}=56$ & 120.17 & 0.24 & 16.68 & 21.0 \\
\hline p-values & 0.0001 & 0.0001 & 0.0001 & 0.0001 \\
\hline
\end{tabular}

CD4= Cluster of Differentiation 4

GPX $=$ Glutathione Peroxidase

$\mathrm{SOD}=$ Superoxide Dismutase

\subsection{Comparison of antoxidant enzyme levels of male HIV subjects on HAART and control subjects}

The CD4 count for male HIV subjects on HAART was $395.80 \pm 185.77 / \mathrm{ml}$, while that of male control subjects was $876.86 \pm 105.77 / \mathrm{ml}$. The mean CD4 counts for HIV subjects were significantly lower than the control $(\mathrm{p}=0.0001)$. The levels of GPX and SOD for male HIV subjects on HAART were significantly lower than the control, while the levels of cortisol were significantly higher in male HIV subjects than the control. There were significant differences in the levels of GPx $\quad(p=0.0476), \quad$ SOD $\quad(p=0.0001)$ and cortisol $(\mathrm{p}=0.0001)$ respectively.

Table 3.2 Showing the comparison of mean values of parameters for male HIV subjects on HAART and control subjects

\begin{tabular}{|c|c|c|c|c|}
\hline & $C D 4 / m l$ & $G P X(\mathrm{ng} / \mathrm{ml})$ & $S O D(\mathrm{pg} / \mathrm{ml})$ & Cortisol $(\mathrm{ng} / \mathrm{ml})$ \\
\hline Male control n=22 & $876.86 \pm 105.77$ & $0.56 \pm 0.27$ & $72.45 \pm 15.14$ & $46.23 \pm 17.05$ \\
\hline Male on HAART n=21 & $395.80 \pm 185.77$ & $0.43 \pm 0.22$ & $38.93 \pm 11.67$ & $91.69 \pm 43.46$ \\
\hline p-values & 0.0001 & 0.0476 & 0.0001 & 0.0001 \\
\hline
\end{tabular}

3.3 Comparison of mean values of parameters for female HIV subjects on HAART and control subjects

The CD4 count for female HIV subjects on HAART was $423.82 \pm 316.43 / \mathrm{ml}$, while that of female control subjects was $846.20 \pm 128.71 / \mathrm{ml}$. There was a significant difference $(p=0.0001)$ in the CD4 counts. The levels of GPX, SOD and cortisol for female HIV subjects on HAART were $0.55 \pm 0.55 \mathrm{ng} / \mathrm{ml}, 39.81 \pm 17.70 \mathrm{pg} / \mathrm{ml}$ and $79.83 \pm 70.92 \mathrm{ng} / \mathrm{ml}$, while the levels for female control subjects were $0.55 \pm$ $0.22 \mathrm{ng} / \mathrm{ml}, \quad 74.89 \pm 17.16 \mathrm{pg} / \mathrm{ml}$ and $40.63 \pm 23.18 \mathrm{ng} / \mathrm{ml}$ respectively. There was no significant difference in the 


\section{International Journal of Science and Research (IJSR) \\ ISSN (Online): 2319-7064 \\ Index Copernicus Value (2013): 6.14 | Impact Factor (2015): 6.391}

levels of $\mathrm{GPx}(\mathrm{p}=0.4970)$. However, significant differences were observed in the levels of SOD $(\mathrm{p}=0.0001)$ and cortisol $(p=0.0010)$ respectively.

Table 3.3: Mean values of parameters for female HIV subjects on HAART and control subjects

\begin{tabular}{|c|c|c|c|c|}
\hline & $C D 4 / m l$ & $\begin{array}{c}G P X \\
(\mathrm{ng} / \mathrm{ml})\end{array}$ & $\begin{array}{c}\text { SOD } \\
(\mathrm{pg} / \mathrm{ml})\end{array}$ & $\begin{array}{c}\text { Cortisol } \\
(\mathrm{ng} / \mathrm{ml})\end{array}$ \\
\hline Female control & $846.20 \pm$ & $0.55 \pm$ & $74.89 \pm$ & $40.63 \pm$ \\
$\mathrm{n}=34$ & 128.71 & 0.22 & 17.16 & 23.18 \\
\hline Female on ART & $423.82 \pm$ & $0.55 \pm$ & $39.81 \pm$ & $79.83 \pm$ \\
$\mathrm{n}=39$ & 316.43 & 0.55 & 17.70 & 70.92 \\
\hline $\mathrm{p}$-values & 0.0001 & 0.4970 & 0.0001 & 0.0010 \\
\hline
\end{tabular}

\section{Discussion}

The results of this research work indicate that HIV patients had significantly lower CD4 counts than the control subjects. This is probably because HIV causes apoptosis in the infected cells [18] and it is capable of enhancing oxidative stress [1], which in turn leads to apoptosis of Tcells, hence the loss of CD4 cells in HIV patients [19]. The increased CD4 count of HIV patients on antiretroviral treatment is probably due to the suppression of viral replication by HAART [20] and since HIV replication is reduced during treatment with HAART, CD4 count will improve [21]. These findings agree with the work of [22].

There were also significant differences in the levels of antioxidant enzymes in HIV patients compared to the control subjects. The levels of both SOD and GPx were significantly reduced in HIV patients than in control subjects. During HIV infection, there is enhanced oxidative stress due to activation of the immune system, which increases the generation of free radicals. These free radicals deplete the levels of these antioxidant enzymes. The depletion of these enzymes occurs because they are consumed in the process of protecting body cells against reactive oxygen species in humans [23]. HAART has been reported to increase chemically reactive species in humans [24] and has also been associated with increased oxidative stress [25 Antiretroviral therapy therefore exerts a negative effect on the activities of antioxidant enzymes.

Basal cortisol was assayed in the study subjects in order to assess the effects of oxidative stress due to HIV infection and HAART administration on the immune system. The result showed that the level of cortisol differed significantly among the study groups. HIV patients on HAART had significantly higher levels of cortisol than control subjects. This finding agrees with the work of [17]. Cortisol is synthesized by the HPA axis in response to stress. The elevated cortisol levels may be due to stress-related shift of steroid production from adrenal androgens towards cortisol or the increase in the concentration of cortisol-binding globulin (CBG) observed with the disease progression[26].Direct infection of the adrenal gland by HIV has been reported to impair the function of the gland. Many of the drugs used in the treatment of HIV can also interfere with adrenal function [26]. HAART has been reported to increase cortisol level [27]. HAART also been reported to increase chemically reactive species in human [23]. These reactive species probably increase the oxidative stress in the subjects, who are already under oxidative stress due to HIV infection. This state of increased oxidative stress causes a marked increase in the level of cortisol.

HIV-positive male subjects on HAART had significant differences in parameters compared to control subjects. The CD4 count was significantly lower than for control subjects. Also, the levels of SOD and GPx were significantly reduced while cortisol level significantly increased. The results were similar for HIV-positive female subjects, compared to female control subjects. It was observed that females had higher CD4 counts than male. This finding agrees with the work of [28]. The observed higher CD4 counts in females than in male subjects could be due to the immunomodulatory effects of sex steroids, especially estrogen and progesterone $[29,30]$.

There were also significant increases in cortisol levels in HIV positive male and female subjects on HAART compared to the control subjects. This finding agrees with the work of [26].The association between cortisol and decrease in CD4 in HIV subjects suggests that cortisol probably plays an important role in the normal functioning of the immune system through its effects on cytokines and also lymphocytes [31].

The levels of SOD and GPx in HIV positive subjects on HAART were significantly lower than those of control subjects. This is probably because HIV infection increases oxidative stress which may result in oxidative damage [12], and HAART has also been associated with increased oxidative stress [24]. The reduced levels of antioxidant enzymes could be because they are consumed in the process of protecting body cells against reactive oxygen species in humans [14].

The result from this study indicate that the antioxidant enzymes, superoxide dismutase and glutathione peroxidase, were significantly reduced in HIV subjects, while cortisol levels were significantly increased. It was also observed that the levels of the antioxidants enzymes were greatly reduced in HIV patients who were on antiretroviral therapy, while cortisol level increased.

The results indicate that HIV patients are constantly under oxidative stress, and the presence of the infection, HIV drug therapy and increased cortisol levels have negative effects on the immune status of HIV patients. Therefore, there is need for incorporating antioxidants in treating HIV infection in our hospitals.

\section{References}

[1] Gwarzo, M.Y. \& Muhammad, S.A. (2010). Extracellular superoxide dismutase activity and plasma malondialdehyde in human immunodeficiency virus subjects of Kano as surrogate markers of CD4 status, International Journal of Biomedical Science, 6(4), 294-300.

[2] Rote, N.S. (2002). Infection and alterations in immunity and inflammation in McCance, K.L. and Huether, S.E.(Eds). Pathophysiology. St Louis. Mosby Inc. 


\section{International Journal of Science and Research (IJSR) ISSN (Online): 2319-7064 \\ Index Copernicus Value (2013): 6.14 | Impact Factor (2015): 6.391}

[3] Mohan,H. (2010). Textbook of pathology $\left(6^{\text {th }}\right.$ Ed). USA. Jaypee Brothers Ltd.

[4] Birben, E., Sahiner, U.M., Sackesen, C., Erzurum, S. \& Kalayi, O. (2012). Oxidative stress and antioxidant defence. World Allergy Organization Journal, 5(1), 919.

[5] Kabel, A.M. (2014). Free Radicals and antioxidants: role of enzymes and nutrition. World Journal of Nutrition and Health, 2(3), 35-38.

[6] Devasagayam, T.P.A., Tilak, J.C., Boloor, K.K., Sane, K.S., Ghaskadbi, S.S., \& Lele, R.D. (2004). Free radicals and antioxidants in human health: Current status and future prospects. Journal of the Association of Physicians of India, 52, 794-804.

[7] Wentworth, P., Wentworth, A.D. \& Zhy, X. (2003). Evidence for the production of trioxygen species during antibody - catalysed chemical modification of antigen. Proceedings of the National Academy of Science, 100, 1490-93.

[8] Nooris, S. (2012). An overview of oxidative stress and antioxidant system. Scientific Reports, 1(8), 1-9.

[9] Birben, E., Sahiner, U.M., Sackesen, C., Erzurum, S. \& Kalayi, O. (2012). Oxidative stress and antioxidant defence. World Allergy Organization Journal, 5(1), 919.

[10] Kabel, A.M. (2014). Free Radicals and antioxidants: role of enzymes and nutrition. World Journal of Nutrition and Health, 2(3), 35-38.

[11] Friis-Moller, N., Reiss, P. \& Sabin, C.A. (2007). Class of anti-retroviral drugs and the risk of myocardial infarction. New England Journal of Medicine, 356, 1723-35.

[12] Stephensen, C.B., Marquis, G.S., Douglas, S.D., Kruzich,L.A. \& Wilson,C.M. ( 2007). Glutathione, glutathione peroxidase, and selenium status in HIVpositive and HIV- negative adolescents and young adults. American Journal of Clinical Nutrition, 85, 173-181.

[13] Sundaram, M., Saghayam, S., Priya, B., Venkatesh, K.K., Balakrishnan,P., Shankar, E., Murugavel, K.G., Solomon, S. \& Kumarasamy,N. ( 2008). Changes in antioxidant profile among HIV-infected individuals on generic highly antiretroviral therapy in Southern India. International Journal of Infectious Diseases, 12(6), 61-66.

[14] Suresh, D.R., Annam, V., Pratibha,K. \& Prasad, B.V.M. ( 2009). Total antioxidant capacity-a novel early biochemical marker of oxidative stress in HIV infected individuals. Journal of Biomedical Science, 16(61), 186-196.

[15] Guber, H.A \& Farag, A.F. (2011). Evaluation of endocrine function, in McPherson, R.A \& Pincus, M.R. (Eds). Henry's clinical diagnosis and management by laboratory methods. Philadelphia. Elsevier Saunders.

[16] Stewart, P.M. (2003). The adrenal cortex, in Larsen, P.R. Kroneberg, H.M, Melmed, S. \& Polonsky, K.S. (Eds). Williams Textbook of endocrinology. Philadelphia. Saunders.

[17] Sinha, U., Sengupta, N., Mukhopadhyay, P. \& Roy, K.S. (2011). Human immunodeficiency virus endocrinopathy. Indian Journal of Endocrinology and Metabolism, 15(4), 251- 260.
[18] Gil,L., Martinez,G., Gonzalez,I., Tarinas,A., Alvarez,A., Giuliani,A., Molina,R., Tapanes,R., Perez,J. \& Leon,O.S. (2003). Contribution to characterization of oxidative stress in HIV/AIDS patients. Pharmacological Research, 47, 217-224.

[19] Kashou, A.H. \& Agarwal, A. ( 2011). Oxidants and antioxidants in the pathogenesis of HIV/AIDS. The Open Reproductive Science Journal, 3, 154-161.

[20]Clarke, T.R., Barrow, G., Thompson, D., Gibson, R \& Barton, E.N. (2010).Response of first line Highly Active Antiretroviral Therapy using CD4 counts: experience in a university hospital in Kingston. West Indian Medical Journal, 59(4), 439-444.

[21] Ibeh, B.O., Habu, J.B. \& Eze, S.C. (2013). Discordant levels of superoxide dismutase and catalase observed in ART-naïve and experienced patients in Southeastern Nigeria. Journal of Infectious Diseases and Therapeutics, 1, 8-16.

[22] Erhabor, O., Ejele, O.A. \& Nwauche, C.A. (2006). The effects of HAART of Stavudine, Lamivudine and Nevirapine on the CD4 lymphocyte count of HIVinfected Africans: The Nigerian experience. Nigerian Journal of Clinical Practice, 9(2), 128-133.

[23] Awodele, O., Olayemi, S.O., Nwite, J.A. \& Adeyemo, T.A. (2012). Investigation of the levels of oxidative stress parameters in HIV and HIV-TB co-infected patients. Journal of Infection in Developing Countries, 6(1), 79-85.

[24] Ngondi, J.L., Oben, J., Forkah, D.M., Etame, L.H. \& Mbanya, D. (2006). The effect of different combination therapies on oxidative stress markers in HIV infected patients in Cameroon. AIDS Research and Therapy, 3, 19.

[25]Zapanti, E., Terzidis, K. \& Chrousous, G.(2008). Dysfunction of the hypothalamic-pituitary- adrenal axis in HIV infection and disease.Hormones,7(3), 205-216.

[26] Ebuehi, O.A.T., Awolola, A. \& Akanmu, A. (2015). Changes in serum cortisol, thyroid hormones and lipid profiles in Nigerian men and women on first and second line antiretroviral therapy for 52 weeks. International Journal of Virology and Molecular Biology, 4(1), 12 18.

[27] Manolescu, L. \& Marinescu, P. (2013). Sex differences in HIV-1 viral load and absolute CD4 cell count in long term survivors HIV-1 infected patients from Giurgiu, Romania. Revista Romana de Medicinade Laborator, 21, 217-224

[28] Bouman, A., Heineman, M.J \& Faas, M.M. (2005). Sex hormones and the immune response in humans. Human Reproduction Update, 11(4), 411-423

[29]Fish, E.N. (2008). Sex-based differences predispose immune response. National Review of Immunology, 8, 737-744.

[30] Oduenyi, I.A., Fasanmade, O.A., Ajala, M.O. \& Ohwovoriole, A.E. (2013). CD4 counts as a predictor of adrenocortical insufficiency in persons with human immunodeficiency virus: how useful? Indian Journal of Endocrinology and Metabolism, 17(6), 1012-1017 